\title{
CONSIDERAÇÕES SOBRE A CRÍTICA DE BLAISE PASCAL À FILOSOFIA MODERNA DO SÉCULO XVII
}

\author{
RAFAEL RIBEIRO DE ALMEIDA ${ }^{1}$
}

\begin{abstract}
Resumo: O artigo desenvolvido pretende apresentar Blaise Pascal como antípoda do projeto racionalista de modernidade do século XVII (cujo filósofo emblemático é René Descartes). Ao apontar os limites da razão humana, Pascal contrapóe-se ao otimismo racionalista da sua época, cujo projeto reside em levar o homem, somente via razão, ao conhecimento claro e evidente do mundo. Neste sentido, debruçamo-nos sobre sua refinada obra - Pensamentos -, na qual Pascal posiciona-se de modo a compreender a razão humana como não capaz de afirmar algo de essencial ou verdadeiro, podendo o homem, tão somente, perceber alguma aparência das coisas. Ao cabo, a filosofia pascaliana procura indicar que a proposta de esclarecer o mundo através da racionalidade (supostamente) onipotente revela-se, na verdade, como um modo de escamotear a insuficiência humana.
\end{abstract}

Palavras-chave: Pascal; Descartes; Razão; Filosofia Moderna.

De acordo com Descartes, a razão, ou bom senso, que todos os homens têm de maneira igual, significa "o poder de bem julgar e distinguir o verdadeiro do falso" (DESCARTES, 1983, p. 29). Além disso, a nossa imaginação ou os nossos sentidos sensíveis só podem nos assegurar alguma coisa de certo, se o nosso entendimento, necessariamente, intervier (DESCARTES, 1983). Nota-se, então, no que diz respeito ao nosso saber, que desde os fundamentos primeiros até os seus corolários e desdobramentos conclusivos, o que temos o tempo todo é o trabalho constituinte da razão.

Descartes vai além e faz da razão um apanágio do ser humano ao colocá-la como “a única coisa que nos torna homens e nos distingue dos animais” (DESCARTES, 1983, p.

1 Estudante de graduação em Filosofia pela Universidade Estadual de Santa Cruz, Ilhéus, BA. Áreas de interesse: Filosofia Contemporânea e Filosofia Moderna. estudosrafael@gmail.com 
29). Ou seja, fundamenta o homem como um ser substancialmente dotado de razão: "compreendi por aí que era uma substância cuja essência ou natureza consistia apenas no pensar" (DESCARTES, 1983, p. 47).

Neste sentido, se Descartes diz que a razão é, pois, previamente estabelecida como uma exclusividade do homem e, assim, passa a se constituir como determinante na vida humana, é porque este raciocínio se apresenta como um desdobramento do cogito, ergo sum. Se penso, logo existo é porque existo como coisa pensante, isto é, como substância pensante. Com isto, o filósofo do cogito realiza uma das principais inaugurações da modernidade, a saber, a subjetividade, o sujeito, o eu. Através do movimento que parte do interior (eu) para o exterior (mundo), o sujeito passa a ser o grande polo fixo constituinte da verdade.

Contudo, o que nos garante, afinal, que este movimento nos leve, de fato, à verdade? Quer dizer, por que é certo que o “eu”, o sujeito que pensa, pode coincidir com a verdade? Com efeito, é sabido que Descartes se debruça sobre as provas racionais da existência de Deus, neste sentido ele apresenta-o como causa que explica a existência de um ser finito e imperfeito - o eu pensante - , porém dotado da ideia de infinito e de perfeição. Sendo assim, se Deus (res infinita) existe como ser infinito e perfeito, bom e veraz, não pode permitir, pois, o erro sistemático do espírito humano - diferente de um gênio maligno (malin génie) Deus é bom e veraz (bon Dieu), o que garante, assim, o otimismo da nossa crença na razão. Substituindo o malin génie pelo bon Dieu, René Descartes pode afirmar seguramente que conhecer pode corresponder à verdade: as nossas ideias têm fundamento de verdade porque possuem procedência divina: "e por que tudo que existe em nós nos vem dele" (DESCARTES, 1983, p. 50). Então, as coisas que concebemos clara e distintamente são todas verdadeiras, isto porque precisamente Deus existe e é ser perfeito, "pois não seria possível que Deus, que é todo perfeito e verídico, as houvesse posto em nós sem isso [fundamento da verdade]" (DESCARTES, 1983, p. 51).

Desta forma, Descartes faz de Deus, diga-se de passagem, um Deus dos filósofos, um Deus que no limite é a garantia do conhecimento verdadeiro que o homem pode ter. Assim, o bon Dieu é a garantia do otimismo racionalista que pressupóe a clareza subjetiva correspondente com a verdade objetiva. Neste sentido, o racionalismo cartesiano afirma que o subjetivo (o eu pensante) corresponde ao objetivo (verdade), já que há um Deus que assegura a verdade epistemológica. Conclui-se, assim, que, na verdade, o bon Dieu é uma deusa - a deusa-razão, o Deus dos filósofos, e não se pode negar esta certeza metafísica, “a menos que sejamos desarrazoados" (DESCARTES, 1983, p. 51). 
Indo além, a fim de expressar a sua procura por bases seguras para um novo conhecimento, Descartes, de forma genuína e sincera, deixa explícito no Discurso do Método, desde o início, que a despeito das suas ocupaçôes (estudos e viagens), sempre buscou um caminho certo que o levaria a seu horizonte tão obcecadamente almejado. Foi, então, na Alemanha, segundo ele próprio afirma, quando o inverno o encarcerou no seu quarto, só e sem perturbaçôes/paixóes, que ele começou a se entreter com os seus pensamentos, os quais levaramno a conceber um projeto metodológico, fundamentado em duas ideias básicas, quais sejam: i) "não há tanta perfeição nas obras compostas de várias peças, e feitas pela mão de diversos mestres, como naquelas em que um só trabalhou” (DESCARTES, 1983, p. 30); ii) suspender todas as opinióes (e juízos) que até então Descartes conferia credibilidade, e, posteriormente, (re)ajustar tais opinióes e mesmo substituí-las por outras que estejam ao nível da razão: "nunca o meu intento foi além de procurar reformar meus próprios pensamentos, e construir num terreno que é todo meu” (DESCARTES, 1983, p. 33).

A necessidade, então, que o conhecimento tem de uma base de fundamentação inabalável, levou-o a arrolar um novo método (uma cadeia de razôes), que não é outra coisa senão o almejado caminho seguro presente desde a primeira parte do Discurso do Método, que ajudará Descartes a reconstruir (reformular) de forma segura e clara a scientia (conhecimento certo e evidente). Neste sentido, Julian Marías, em Biografia da Filosofia e Ideia da Metafísica, reforça: "Descartes possui um método novo: deseja conduzir bem a sua razão e procurar a verdade nas ciências; uma verdade que não possui, porque está submergido na ignorância e na dúvida” (MARÍAS, 1966, p. 180).

Destaca-se que o método tal como desenvolvido por Descartes possui um caráter de precaução ${ }^{2}$, no sentido de que, dominado pelo temor de errar, tal método - isto é: um caminho rumo à verdade - deve mover-se exclusivamente ao nível da razão, afastando-se, portanto, de (múltiplas) opinióes que desentranhem a dúvida. Assim sendo, nota-se que este é o sentido, conforme ressalta Marías, do

método racionalista. Não se trata nele de uma técnica mental, de um simples processo cognoscitivo para alcançar a verdade; é mais a convicção de que a razão - a

2 Marías, no seu livro História da Filosofia, corrobora o uso preciso do termo: "A primeira tentativa de Descartes é, pois, ficar totalmente sozinho [...]. E a partir deste isolamento tem de tentar reconstruir a certeza ao abrigo da dúvida. Descartes procura, antes de mais, não errar. Começa a filosofia da precanção" (MARÍAS, 1999, p. 216. Grifo nosso). 
Consideraçôes sobre a crítica de Blaise Pascal à filosofia moderna do século XVII

razão tal como se entende no século XVII, isto é, as ideias claras e distintas - é o órgão que apreende sem mais a realidade (MARÍAS, 1966, p. 180).

Ao cabo, René Descartes afirma: "notando que esta verdade: eu penso, logo existo, era tão firme [...], julguei que podia aceitá-la, sem escrúpulo, como o primeiro princípio da filosofia que procurava” (DESCARTES, 1983, p. 46. Grifo nosso).

Posto isto, tal projeto cartesiano acaba por inaugurar e, ao mesmo tempo, ser um modelo da modernidade filosófica iniciada cronologicamente no século XVII. Outros filósofos - na zona filosófica cartesiana - do século XVII também se debruçaram, de um jeito ou de outro, sobre vários pontos já então almejados pelo filósofo do cogito:

Descartes representa porém apenas o começo da metafísica racionalista. Inaugura de um modo efetivo a modernidade, e em sua figura salientam-se perfeitamente os traços inovadores; a partir dele acentuar-se-á a compreensão das raízes intelectuais da nova filosofia (MARÍAS, 1966, p. 182).

Neste sentido, podemos destacar alguns filósofos em particular, no sentido de que eles abordam por excelência o projeto racionalista de modernidade encabeçado por $\mathrm{R}$. Descartes. São eles: Baruch Espinosa, Gottfried Leibniz ${ }^{3}$ e Nicolas Malebranche: "do racionalismo [...], seus pensadores mais estritamente filosóficos e representativos: Descartes, Malebranche, Spinoza, Leibniz” (MARÍAS, 1966, p. 194. Grifo nosso). Não só pela proximidade cronológica do século XVII, mas, sobretudo, pela afinidade conceitual que há entre eles; assim sendo, tais pensadores estão unidos "por uma preocupação comum: o método do conhecimento. Concretamente, este modo de pensar define-se pelo exercício exclusivo da razão [...] e pela tendência a apreender a realidade com conceitos matemáticos” (MARÍAS, 1966, p. 174. Grifo nosso).

Dialogando entre si, direta ou indiretamente, tais filósofos dedicaram-se a uma série de problemas já muito caros a Descartes. Por exemplo: i) a razão como apanágio do homem, sendo este, portanto, determinado como um ser que pensa (Descartes, Espinosa, Male-

3 De Descartes, Leibniz (1646-1716) herda a pretensão de fazer da filosofia uma espécie de cálculo filosófico, matematizando-a a fim de encontrar o conhecimento universal, ou seja, um saber que se caracteriza pela totalidade do conhecimento humano. No livro Dissertação Sobre a Arte Combinatória, Leibniz procurou encontrar para a filosofia leis que fossem tão certas quanto as matemáticas. No limite, sua filosofia acaba por desaguar na concepção segundo a qual o mundo é tido como rigorosamente racional e como o melhor dos mundos possí veis. 
branche): "O homem é definido por sua participação da razão: animal rationis particeps" (MARÍAS, 1966, p. 185); ii) a onipotência da razão em detrimento dos sentidos, imaginação e paixões do homem (Descartes, Espinosa ${ }^{4}$, Malebranche): Julian Marías, no seu texto História da Filosofia, corrobora: "Descartes funda a sua especulação no critério da evidência. Esta evidência não se refere à percepção nem aos sentidos, que nos enganam com frequência, mas à clareza e à distinção das ideias; é a evidência da razão" (MARÍAS, 1999, p. 224); iii) as formas racionais de conhecer e de conceber Deus, não passando, então, de um Deus dos filósofos, o qual serve de fundamento metafísico da verdade alcançável via razão (Descartes, Espinosa): “O problema de Deus ocupa toda a metafísica do século XVII" (MARÍAS, 1966, p. 194); iv) a rejeição por excelência do discurso de autoridade, ou seja, a recusa da tradição em prol de uma reformulação do pensamento humano (Descartes, Malebranche): “É certo que Descartes [...] se apresenta quase sem alusões a sua tradição filosófica, em certo sentido mascarado (larvatus prodeo), e isto tornou possível uma interpretação 'renascentista' de seu pensamento" (MARÍAS, 1966, p. 179); v) e por último, uma ideia que atravessa todos os mencionados pensadores (Descartes, Espinosa, Leibniz e Malebranche), a saber: "Toda a metafísica vai passar a basear-se no eu. A história desta tentativa é a história da filosofia moderna” (MARÍAS, 1999, p. 218). Em vista disso, podemos concluir:

\footnotetext{
Estes são os elementos que os grandes filósofos do século XVII encontram em sua circunstância mental. Neste complexíssimo mundo de ideias terão eles que se mover, recebendo influências de alcance e fecundidade muito díspares, que exigirão o serem ordenadas numa perspectiva (MARÍAS, 1966, p. 175).
}

Assim, posto brevemente os esclarecimentos sobre o projeto racionalista de modernidade do século XVII, cujo filósofo emblemático é René Descartes, passaremos então a tratar propriamente de Blaise Pascal.

\footnotetext{
4 Com efeito, com Baruch Espinosa (1632-1677) o racionalismo (de total influência cartesiana) é ainda mais exacerbado no que diz respeito à onipotência da razão em detrimento de nossa capacidade imaginativa. Por um lado, Espinosa muito condensa sua crítica à superstição em todas suas formas: segundo diz, a superstição está diretamente associada à imaginação que, impotente para compreender as leis do universo, oscila entre o medo e a esperança. Ele se debruça sobretudo na superstição religiosa, atacando-a ao sustentar que é possível conhecer racionalmente Deus. Por outro lado, Espinosa procura desfazer os resquícios de mistérios subjacentes ao conhecimento racional, caracterizando-se, deste modo, por um racionalismo absoluto. Neste ponto, ele se lança no combate ao irracionalismo que seria uma pseudoforma de conhecimento relacionado, por sua vez, também à imaginação.
} 
Com efeito, este capítulo de nossa investigação versará propriamente sobre o modo pascaliano de compreender a razão humana como não capaz de afirmar algo de essencial acerca do mundo.

\footnotetext{
Afinal, que é o homem dentro da natureza? Nada em relação ao infinito; tudo em relação ao nada; um ponto intermediário entre tudo e nada. [...] Que poderá fazer [o homem], portanto, senão perceber alguma aparência das coisas num eterno desespero por não poder conhecer nem seu princípio nem seu fim? (PASCAL, Br. ${ }^{5}$ Frag. 72, 1984, p. 52).
}

Segundo Pascal, antes do pecado original o homem encontrava-se em estado de perfeição em união pacífica com Deus. Não estava, então, a mercê da dor e da tristeza. Dessa forma, Adão, homem primevo, antes de pecar era livre e não jazia no drama da miséria; só a partir de seu erro, que se tornou a queda adâmica, perdeu a sua liberdade e, com a queda, toda a natureza humana entrou em decadência e se tornou corrompida, viciosa e viciada. Neste sentido, na carta escrita na ocasião do falecimento de seu pai, Pascal reconhece que a morte antes do pecado era odiada, por assim dizer, já que separava uma alma santa de um corpo santo (vida inocente); contudo, a partir do pecado original, a morte passou a ser desejada, uma vez que separa uma alma santa de um corpo impuro (vida concupiscente): “a morte é um castigo do pecado, imposto ao homem para expiação de seu crime, necessária ao homem para a purga ção de seu pecado" (PASCAL, $1965^{6}$, p. 186). Para Pascal a queda arrasta consigo toda a condição humana: esta, após a queda, passa a estar debilitada e escrava da concupiscência. Indo além, a própria insuficiência da razão humana, na perspectiva pascaliana, deve-se por excelência à sua situação existencial de queda adâmica, conforme constata Sofia Rovighi ao comentar Os limites da razão em Pascal (capítulo que faz parte do seu livro História da Filosofia Moderna): "Essa impotência da razão não depende, segundo Pascal, da natureza da própria razão, da essência do homem, mas da sua situação existencial" (ROVIGHI, 1999, p. 152. Grifo nosso).

5 Em nota, Sérgio Milliet, o tradutor da obra original (Pensées), observa: "A ordenação dos Pensamentos de Pascal, que é seguida nesta edição e que já se tornou clássica, se deve a Brunschvicg” (PASCAL, 1984, p. 7).

6 Citamos Pascal a partir da "Coletânea do pensamento de Blaise Pascal”, organizada por François Mau riac. No caso desta citação, a coletânea faz referência à obra de Pascal: Pensamento em torno da morte. 
De saída, então, temos uma perspectiva pascaliana de homem que muito o afasta do projeto racionalista de seu tempo, tendo em vista que tal projeto fundamenta o homem como um ente racional: "Portanto, o método cartesiano é o racionalismo. A única instância com valor para o homem é a razão que é comum a todos. O homem é substância pensante, raison. Esta é uma das raízes da ciência apriorística do séc. XVII” (MARÍAS, 1999, p. 224). Desta forma, nota-se que o racionalismo de modelo cartesiano e os filósofos implicados neste modelo fundamentam o homem a partir do ato de conhecer racionalmente, quer dizer, o homem é concebido como um ser substancialmente dotado de razão ${ }^{7}$.

Sendo assim, evidencia-se que diferente do projeto racionalista da sua época, Pascal não confere otimismo e confiança - tal como o racionalismo da sua época - ao poder da razão, ou, conforme observa Rovighi ao discutir o papel da insuficiência da razão em Pascal: "Pascal, portanto, não tem confiança na razão humana como órgão, digamos assim, para resolver o problema da vida” (ROVIGHI, 1999, p. 152). E mais: “a razão humana, o pensamento, o esprit, não é suficiente para conduzir o homem à sua perfeição” (ROVIGHI, 1999, p. 160). Segundo Pascal, na verdade o homem configura-se enquanto um ser miserável e extraviado, sempre sujeito à mudança e ao devir, com uma duração de vida efêmera. Ademais, o homem é um "caniço" queda adâmica, infeliz e fraco, mentiroso e hipócrita:

A vida humana nada mais é que uma perpétua ilusão; não fazemos outra coisa senão nos enganarmos e adularmos mutuamente. [...] O homem não passa, portanto, de disfarce, mentira e hipocrisia, tanto em face de si próprio como em relação aos outros (PASCAL, Br. Frag. 100, 1984, p. 66).

Ao adentrar no subsolo da natureza humana, Pascal estuda aquilo que ele chama os divertimentos (divertissement): tudo que proporciona aparente felicidade aos homens, fazendo-os esquecer, assim, da sua condição de ser miserável. Ledo engano, porém, entender tal divertimento como uma forma tranquila de conduzir a vida; mas, isto sim, trata-se neste caso

7 Consoante a esta afirmação, destacam-se a citação de Descartes (1983, p. 29): “[a razão é] a única coisa que nos torna homens e nos distingue dos animais"; a citação de Espinosa (1983, p. 47): "o homem é um animal racional"; a citação de Leibniz (1984, p. 388): "aqui a consideramos [a razão] como uma faculdade, pela qual su pomos que o homem se distingue do animal e o supera de muito; por último, a de Malebranche (2004, p. 42): “a alma [sinônimo de razão] é a parte principal do ser”. Com exceção deste último filósofo, todas as demais citações estão na coleção Os Pensadores, conforme indicado na referência bibliográfica.

8 "O homem não passa de um caniço, o mais fraco da natureza" (PASCAL, Br. Frag. 347, 1984, p. 123). 
da busca incessante de ruído, busca de inconstância de modo a desviar o homem de pensar a sua própria condição, já que o diverte: "A nulidade deste nosso ser nos é revelada no sentido do tédio. O tédio é o sentido do nosso nada, e esse sentido nos pesa, nos dá uma tristeza insuportável. Daí a inconstância, a busca de mudança, do divertissement" (ROVIGHI, 1999, p. 159). Daí, pois, o porquê de tanto amarem os homens o ruído, o tumulto e a agitação; daí o porquê ser a prisão um suplício tão horrível e o prazer da solidão tornar-se algo tão incom preensível e remoto; o repouso, neste caso, equivale mesmo à punição: "Quando um soldado se queixa das penas que teve, ou um lavrador, etc ... obriguem-nos a ficar sem fazer nada" (PASCAL, Br. Frag. 130, 1984, p. 70).

Neste sentido, os divertimentos desviam os homens da visão da morte e da sua miséria. Consoante a isso, o próprio filósofo afirma em Pensamentos:

nada é mais insuportável ao homem do que um repouso total, sem paixões, sem negócios, sem distrações, sem atividade. Sente então seu nada, seu abandono, sua insuficiência, sua dependência, sua impotência, seu vazio. Incontinenti subirá do fundo de sua alma o tédio, o negrume, a tristeza, a pena, o despeito, o desespero (PASCAL, Br. Frag. 131, 1984, p. 70).

Seguindo o raciocínio, o problema propriamente apontado por Pascal no que diz respeito à busca dos homens pelo tumulto, não consiste exatamente na procura enquanto tal, caso só procurassem por mera diversão; acontece que procuram para se tornarem (imaginarem-se) felizes, esquecendo-se da natureza infeliz do homem. Pascal afirma que a procura pelo divertimento acaba mesmo por se revelar como um movimento de tentar mascarar, fazer esquecer, fazer desviar o homem do encontro com sua condição. Eis, neste sentido, a seguinte caricatura humana: um ser de condição infeliz que procura, todavia, ser feliz ao tentar esquecer que é infeliz. Em sua obra Pensamentos Pascal diz: "descobri que toda a felicidade dos homens vem de uma só coisa, que é não saberem ficar quietos dentro de um quarto" (PASCAL, Br. Frag. 139, 1984, p. 72).

Posto isto, por mais triste que esteja uma pessoa, se porventura entrar num dado divertimento, será, então, feliz durante este tempo, ao passo que, o homem mais feliz de todos, se não estiver se divertindo ou se ocupando com qualquer coisa que impeça de espraiar seu tédio, ficará, de abrupto, logo infeliz; com o divertimento só há felicidade, porque sem o divertimento os homens veriam a si mesmos, de modo a refletir no que são. 
pouco que temos de ser impede-nos a visão do infinito (PASCAL, Br. Frag. 72, 1984 , p. 53).

Com efeito, na coletânea de textos de Pascal nomeado O Pensamento vivo de Pascal, o comentador François Mauriac apresenta o filósofo francês e nos diz:

\begin{abstract}
deve ter sentido muitas vezes, na companhia de seus amigos cheios de força e de entusiasmo, a profunda fadiga de um homem indiferente dos demais e cuja natureza não levava à diversão mas sim à concentração, de um homem que se esforçava por viver fora de si quando todo o seu gênio o impelia para a introversão e o melhor conhecimento de si próprio (PASCAL, $1965^{\circ}$, p. 10).
\end{abstract}

Com isto, gostaríamos de chamar atenção pelo relevante incômodo de Pascal para com o falso e superficial otimismo da sua época, com o qual os homens buscavam iludir a si e aos outros. No ápice do entusiasmo proporcionado aparentemente pelo divertimento, os homens procuram iludirem-se a si mesmos, imaginando que poderiam ser felizes uma vez alcançando o objeto de tal divertimento. Além disso, o ser humano é tão oco, vazio e vão "que estando cheio de mil causas essenciais de tédio, a menor coisa, como um taco e uma bola que ele empurra, basta para diverti-lo" (PASCAL, $1965^{10}$, p. 106).

Acontece que, ao procurar o repouso no tumulto faz-se mister combater algumas adversidades, e, quando elas são superadas, o repouso torna-se, então, insuportável pelo tédio que cria. E, prosseguindo o círculo, volta-se atrás do tumulto, a fim de encontrar novo repouso, mesmo que para isso precise superar novas adversidades.

No limite, o homem não vai contemplar seu propósito de felicidade na vida ordi nária dos divertimentos, pois, em última instância, a infelicidade, o tédio, a baixeza, são todos estes elementos naturais do homem, naturais no sentido de depois da queda adâmica: "Descrição do homem: dependência, desejo de independência, necessidade” (PASCAL, Br. Frag. 126, 1984, p. 70); e mais: "Condição do homem [após a queda adâmica]: inconstância, tédio, inquietação” (PASCAL, Br. Frag. 127, 1984, p. 70). Seguindo o raciocínio, portanto, por mais que os homens se coloquem no afã de encontrarem divertimentos, por outro lado, eles não deixarão de serem, certamente, infelizes, isto devido ao próprio estado da sua compleição - "Um homem vive com prazer em seu lar: que encontre uma mulher atraente, que jogue 
cinco ou seis dias com alegria, ei-lo miserável ao tornar à sua ocupação primeira. Nada é mais comum” (PASCAL, Br. Frag. 128, 1984, p. 70).

Seguindo o raciocínio, se por um lado Pascal afirma que o homem procura o divertimento e a iludir-se a si mesmo, por outro, ele afirma que o homem também comporta uma qualidade que o faz reconhecer, e não mascarar, a própria condição de miserabilidade, a saber, a qualidade de pensar - de ter consciência - acerca da sua situação: "Não é miserável sem ter-se consciência. Uma casa em ruínas não o é. Só o homem é miserável. Ego vir videns [Lamentaçôes de Jeremias 3,1]" (PASCAL, Br. Frag. 399, 1984, p. 132). Portanto, reconhecer, pensar a própria condição insuficiente caracteriza a grandeza humana, que junto com a miséria constitui o paradoxo que jaz na natureza do homem. Segundo Sofia Rovighi (1999, p. 159), a "análise pascaliana do homem orienta-se em torno destes dois pólos: miséria e grandeza do homem". Posto isto, eis o homem: alguém capaz de muito e pouco, capaz de tudo e de nada, ou seja: "O homem não é anjo nem animal; e, por infelicidade, quem quer ser anjo é animal” (PASCAL, Br. Frag. 358, 1984, p. 125).

Neste sentido, se é verdade, como quer Pascal, que "O homem não passa de um caniço, o mais fraco da natureza”, mais para adiante ele completa o raciocínio: "mas é um caniço pensante" (PASCAL, Br. Frag. 347, 1984, p. 123). Assim, o pensamento recebe grande destaque na filosofia pascaliana; todavia, pensar em quê? Com efeito, a grandeza do pensar, neste caso, consiste justamente em se reconhecer na condição (após a queda adâmica) de miserável: "A grandeza do homem é grande na medida em que ele se conhece miserável. Uma árvore não sabe que é miserável. É, pois, ser miserável conhecer-se miserável; mas é ser grande saber que se é miserável” (PASCAL, Br. Frag. 397, 1984, p. 132). Ou seja, como o próprio filósofo francês explicita, por mais

que o universo o esmagasse, o homem seria ainda mais nobre do que quem o mata, porque sabe que morre e a vantagem que o universo tem sobre ele; o universo desconhece tudo isso. Toda a nossa dignidade consiste, pois, no pensamento. [...] Trabalhemos, pois, para bem pensar (PASCAL, Br. Frag. 347, 1984, p. 123-124. Grifo nosso).

Consoante à citação acima, destaca-se mais uma vez a contraposição de Pascal em relação ao racionalismo hegemônico no século XVII, pois, enquanto os filósofos implicados neste projeto diferenciavam o homem do animal pela capacidade racional, Pascal, porém, diferencia a natureza humana da animal no sentido de que no homem, por sua vez, há a possibilidade do (re)conhecimento - do pensamento mesmo - acerca da sua condição mísera; isto 
é: a impossibilidade de equiparar o homem aos animais, no caso de Pascal, deve-se à possibilidade que o homem tem de ter consciência da sua miséria.

Com efeito, considerando a postura de nosso filósofo sobre a condição do homem, qual seria, afinal, o lugar do cristianismo na visão pascaliana? Segundo o que ele próprio diz, "A religião cristã ensina, portanto, aos homens estas duas verdades a um tempo: que há um Deus que os homens são capazes de atingir e que há uma corrupção na natureza que os torna indignos" (PASCAL, Br. Frag. 556, 1984, p. 173-174). Ou seja, ainda que uma vez reconhecida a miséria é mister ao homem voltar-se para Deus, aliás, mais do que isso, uma vez aquele que profundamente reconhece sua miséria, enquanto natureza humana, sentirá, por excelência, a necessidade de Deus, já que só este pode reparar verdadeiramente a miséria do homem, conforme corrobora Sofia Rovighi: "sem a fé, isto é, sem a aceitação dessa misericórdia divina, o homem não resolve o problema da vida” (ROVIGHI, 1999, p. 161).

Tendo isso em vista, faz-se oportuno um adendo: quando pensamos no Deus referido por Pascal, deve-se ter claro que se trata não do Deus dos filósofos, mas sim

o Deus de Abraão, o Deus de Isaac, o Deus de Jacó, o Deus dos cristãos, é um Deus de amor e consolação; é um Deus que enche a alma e o coração daqueles que o possuem; é um Deus que lhes faz sentir interiormente a própria miséria e a sua infinita misericórdia (PASCAL, Br. Frag. 556, 1984, p. 174-175).

Com isto, Pascal afasta-se de seus contemporâneos os quais se lançam no projeto de onipotência da racionalidade, a qual tem acesso inclusive aos mistérios de Deus. Descartes o apresenta como princípio metafísico que garante a verdade do pensamento e o otimismo da nossa crença na razão, isto é, um Deus que, na verdade, é um deus ex machina epistemológico $^{11}$. Espinosa (1983), por sua vez, afirma que Deus é a causa racional produtora de todas as coisas, segundo leis que os homens podem conhecer plenamente através da razão, e, mais do que isso, diz que toda filosofia que apele para um Deus transcendente na verdade será apenas um eufemismo de superstição refinada. Por último, Leibniz (1984) diz que o mundo criado por Deus está impregnado de racionalidade, cumprindo, assim, teleologicamente objetivos propostos pela sua própria mente divina. Neste sentido, podemos concluir: "Vemos assim

11 "Descartes, não sempre de um modo claro e explícito, recorre a Deus, que, por ser criador das duas substâncias finitas, estabelece entre elas um vínculo ontológico, o de ambas constituirem um só ens creatum; é este o sentido metafísico do argumento do gênio maligno, que obriga a demonstrar a existência de Deus para assegurar-se de sua 'veracidade', isto é, para que garanta a correspondência das substâncias, e, portanto, a verdade das ideias claras e distintas" (MARÍAS, 1966, p. 193). 
como todos os sistemas do racionalismo se fundam em Deus, e se consideram impossível seu conhecimento natural, pelo menos necessitam provar sua existência, como garantia de toda verdade” (MARÍAS, 1966, p. 187).

Portanto, afastando-se dos filósofos que tinham necessidade de Deus apenas para utilizá-lo como justificativa - quer dizer, para explicar racionalmente o universo - Pascal destaca que não podemos entender Deus (infinito) através da racionalidade (finita e insuficiente). De acordo com Pascal:

\footnotetext{
Mesmo se um homem estivesse persuadido de que as proporções dos números são verdades imateriais, eternas e dependentes de uma primeira verdade em que subsistem, e que se chama Deus, eu não o julgaria ainda muito adiantado em sua salvação. O Deus dos cristãos não consiste num Deus simplesmente autor de verdades geométricas e da ordem dos elementos; essa é a porção dos pagãos (PASCAL, Br. Frag. 556, 1984, p. 174).
}

Neste sentido, diante da indagação se Deus existe ou não existe, a razão não pode determinar para qual lado nos inclinamos, tendo em vista que:

Conhecemos a existência do infinito e ignoramos a sua natureza, porque tem extensão, como nós, mas não limite como nós. Não conhecemos nem a existência nem a natureza de Deus, porque não tem extensão nem limites (PASCAL, Br. Frag. 233, 1984, p. 94).

Oposto à perspectiva cartesiana, portanto, a filosofia pascaliana não visa alcançar Deus mediante a razão, mesmo se esta for de grande magnitude.

Dessa forma, chegamos ao ápice central da problemática abordada neste texto: se por um lado o século XVII é marcado pelo projeto racionalista que valoriza a razão a ponto de podermos atingir o conhecimento claro e distinto da verdade, Pascal, enquanto figura ímpar, reconhece que a razão não pode afirmar absolutamente nada de verdadeiro, podendo o homem, apenas, perceber alguma aparência do mundo.

Ao passo que foi este precisamente o objeto do projeto da modernidade de modelo cartesiano, foi também este o ponto no qual precisamente tropeçou; tropeçou porque, como diz Pascal "falta-nos uma capacidade infinita, e creio que quem tivesse compreendido os princípios últimos das coisas chegaria também a conhecer o infinito” (PASCAL, Br. Frag. 72, 1984, p. 53). Com efeito, a Terra a qual o homem pertence, aparece-lhe "como um ponto na órbita ampla desse astro, e que se maravilha de ver que essa amplitude tampouco passa de um ponto insignificante na rota dos outros astros que se espalbam pelo firmamento" (PASCAL, Br. 
Frag. 72, 1984, p. 51. Grifo nosso). Mesmo se ampliássemos nossas concepções acabaríamos por encontrar tão somente um átomo em comparação com a realidade das coisas: "todo esse mundo visível é apenas um traço imperceptível na amplidão da natureza, que nem sequer nos é dado conhecer mesmo de um modo vago" (PASCAL, Br. Frag. 72, 1984, p. 51).

Assim, pergunta-se Pascal: o que é o homem dentro do infinito?

que o homem, voltado para si próprio, considere o que é diante do que existe; que se encare como um ser extraviado neste canto afastado da natureza, e que, da pequena cela onde se acha preso, isto é, do universo, aprenda a avaliar em seu valor exato a terra, os reinos, as cidades e ele próprio. Que é um homem dentro do infinito? (PASCAL, Br. Frag. 72, 1984, p. 51. Grifo nosso).

Nada em relação ao infinito. Mas tudo em relação ao nada. Eis, então, o homem: um ponto intermediário entre os extremos do tudo e nada. E ainda, incapaz de compreender os dois extremos, "é-lhe igualmente impossível ver o nada de onde saiu e o infinito que o envolve” (PASCAL, Br. Frag. 72, 1984, p. 52). Neste sentido, impedidos de conhecer os dois extremos, não podemos conhecer senão alguma aparência das coisas "num eterno desespero por não poder conhecer nem seu princípio nem seu fim?” (PASCAL, Br. Frag. 72, 1984, p. 52). Nossa razão está sempre se iludindo com a inconstância aparente das coisas e desde que compreendemos isso, melhor será e nos manteremos tranquilos: "que importa que um homem tenha um pouco mais inteligência das coisas? Se a tiver, as verá de um pouco mais alto" (PASCAL, Br. Frag. 72, 1984, p. 54), mas ainda será um termo médio que flutua entre dois extremos. E, ademais, a duração de nossa vida por mais que se prolongue por dez ou cinquenta anos, "não será igualmente ínfima na eternidade?” (PASCAL, Br. Frag. 72, 1984, p. 54).

Devido à queda adâmica (pecado de Adão), o cristianismo de Blaise Pascal é marcado por uma situação de miserabilidade do ser humano. O pecado primevo fez do homem um ser miserável, corrompido e fendido; a partir da queda adâmica, o homem perdeu sua liberdade e, com a queda, toda a natureza humana entrou em decadência e se tornou corrompida, viciosa e viciada. Neste sentido, Pascal indica que o homem procura desviar-se quanto ao pensamento (quanto à consciência) de tal condição, quer dizer: adentrando no subsolo da natureza humana, Pascal estuda os divertimentos que proporcionam (aparente) felicidade aos 
homens, fazendo-os esquecer, assim, da sua frágil condição. Com isto, ele quer combater o otimismo superficial da sua época, já que Pascal rejeita a busca humana de felicidade que consiste em evitar a (enxergar a sua) infelicidade intrínseca. Ao contrário, ele diz que a grandeza humana consiste em reconhecer, saber e pensar a própria condição de homem insuficiente. Posto isto, o corolário de tal reconhecimento acaba por desaguar na necessidade que temos de Deus, já que só este pode reparar verdadeiramente a miséria do homem.

Assim sendo, contemplamos o escopo do presente trabalho: ao passo que o projeto racionalista de modernidade do século XVII valoriza a razão a tal ponto de, por meio dela, podermos atingir o conhecimento claro e distinto da verdade, procuramos apresentar Pascal como antípoda do paradigma racionalista de conhecimento, ao evidenciar que o filósofo francês indica por excelência os limites e insuficiência da razão humana. Assim, pergunta-se Pascal: o que o homem é diante do que existe? Nada em relação ao infinito, mas tudo em relação ao nada, ou seja: um ponto finito entre o tudo e nada. 


\section{REFERÊNCIAS BIBLIOGRÁFICAS}

BROUGHTON, J.; CARRIERO, J. (org.). Descartes. Porto Alegre: Penso, 2011.

DeSCARTES, R. Discurso do Método. 3. ed. São Paulo: Abril Cultural, 1983. (Coleção Os Pensadores)

ESPINOSA, B. Tratado da correção do intelecto. 3. ed. São Paulo: Abril Cultural, 1983. (Coleção Os Pensadores)

LEIBNIZ, G. W. Novos Ensaios Sobre o Entendimento Humano. 2. ed. São Paulo: Abril Cultural, 1984. (coleção Os Pensadores)

MALEBRANCHE, N. A Busca da Verdade. São Paulo: Discurso Editorial, 2004.

MARÍAS, J. Biografia da Filosofia e Ideia da Metafísica. Tradução Diva R. de Toledo Piza. São Paulo: Duas cidades, 1966.

MARÍAS, J. História da Filosofia. 7.ed. Tradução Alexandre Pinheiro Torres. Porto: Sousa \& Almeida, 1999.

PASCAL, B. Coletânea do pensamento de Pascal. Mauric François (org.). São Paulo: Martins, 1965.

PASCAL, B. Pensamentos. 3. ed. Tradução Sérgio Milliet. São Paulo: Abril Cultural, 1984. (Coleção Os Pensadores)

ROVIGHI, S. História da Filosofia Moderna - da revolução cientifica a Hegel. Tradução Marcos Bagno e Silvana Cobucci Leite. São Paulo: Loyola, 1999. 